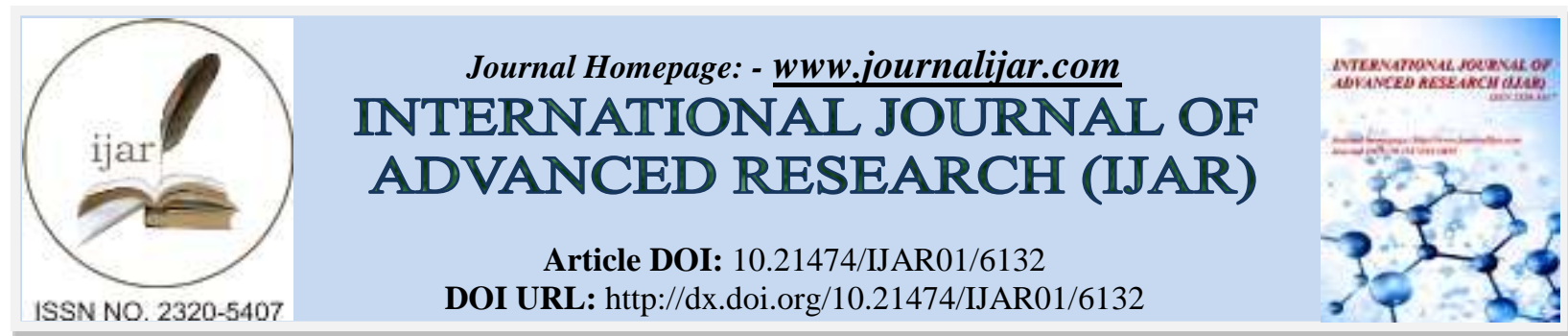

RESEARCH ARTICLE

\title{
EXPLORING THE EFFECT OF NANOTECHNOLOGY PROCESS ON PHYSICAL AND CHEMICAL PROPERTIES OF HERBS: A SHORT REVIEW.
}

\author{
Norhidayah. $A^{2}$, Noriham. $A^{1}$ and Rusop. M. $D^{3}$. \\ 1. Faculty of Applied Science, Universiti Teknologi MARA Shah Alam, Selangor. \\ 2. Faculty of Hotel and Tourism Management, Universiti Teknologi MARA Selangor. \\ 3. NANO-SciTech Centre, Institute of Science, Universiti Teknologi MARA Shah Alam, Selangor.
}

\section{Manuscript Info \\ Manuscript History \\ Received: 22 October 2017 \\ Final Accepted: 24 November 2017 \\ Published: December 2017}

Key words:-

Nanotechnology, Physical Properties,

Chemical Properties, herbs.

\begin{abstract}
Nanotechnology is the technology involves in the manufacturing and development of materials in the nanoparticle dimension which is less than $100 \mathrm{~nm}$. However, due to numerous successful applications by employing nanomaterial with particle size above $100 \mathrm{~nm}$, it is agreed that cut off $100 \mathrm{~nm}$ for nanoparticle is arbitrary. Thus nanoparticle is also define as particles in the range of $10 \mathrm{~nm}$ to $1000 \mathrm{~nm}$. Abundance of studies being conducted to produce nanoparticles from herbs and this has become a core research area in many countries around the world. The potential of the nanotechnology process application in food research is in the spotlight and has attracted much attention in many countries recently due to the outstanding properties of nanoparticles which cannot be found in the bulk material. The smaller particle size developed through the nanotechnology process is reported to have high water-holding capacity, high fluidity and a high water solubility index. Moreover, the easy penetration of nanoparticle into the structure of food, well disperse and increases in the nutritive component make the nanotechnology process an interesting alternative technology to be applied in the food industry.
\end{abstract}

Copy Right, IJAR, 2017,. All rights reserved.

\section{Introduction:-}

The term "nanotechnology" was first used in 1974 by the late Norio Taniguchi and the concepts were provided by Richard Feynman in 1959. It has currently become a fast emerging field that involves the manufacture, processing, food and bioprocess industry through the development of materials in the nanoscale dimension of less than $100 \mathrm{~nm}$ to $1000 \mathrm{~nm}$ (Bouwmeester et al., 2009). This is a rapid growing technology and is becoming an important tool to be applied in improving the agribusiness sector include food industry. It is estimated that nanotechnology will give significant effect on the growth of agribusiness industry in the next 10 years. In fact, nanotechnology has predicted to improve the entire food industry by changing the way food is produced, processed, packaged, transported, and consumed (Sabourin \& Ayande, 2015). Hence, abundance research related to nanotechnology process related to food has been conducted. Homogenisation and fine milling of milk and dairy product into droplets of less than 100 $\mathrm{nm}$ in size are already established. The study on the development of nanoparticle in food was carried out mainly to improve the functional properties of food. Several researchers have confirmed the water solubility and bioavailability, as well as the antioxidant enhancement attained in the sample that went through the nanotechnology process (Gao et al., 2011; Liu et al., 2008; Ma et al., 2009). This is in line with other researchers who have claimed 
that the reduction in particle size can improve the bioactivity of the material (Zhao et al., 2009). In conjunction with the nanotechnology process benefits provided, recently the research is moving towards the role of the nanotechnology process in food research in enhancing the bioactivity of herbs.

\section{The Effect of Nanotechnology Process on Physical Property of Biomaterial:-}

Nanotechnology process significantly affects the physical properties of the material tested. Reduction in the particle size into the nanometer and shifting of a broad particle size distribution into a bimodal sharp peak distribution were the obvious effects of the nanotechnology process. It was the energy generated during the nanotechnology process that transmitted the energy to the internal part of the granule, then spread it throughout the granule, therefore forcing the granule to breaking point. In addition, the effect of various form of forces including compression, impact, shear, and attrition force assisted the physical breakdown of particles. The forces break the particles into smaller particles and at the same time split the finer particles from larger aggregate particles. Hence a uniform distribution of loose and porous smaller particles were produced (Kazemimostaghim et al., 2013; Ren et al., 2010).

Theoretically, below $100 \mathrm{~nm}$ size of particles are expected to be formed as a result of the nanotechnology process application, but somehow many authors proved that the particle sizes produced were greater than $100 \mathrm{~nm}$. Even though a nanoparticle is defined as a particle of a size less than $100 \mathrm{~nm}$, however it actually depends on the type of material used. Relatively, the composition of material used may become one of the limitations in reducing the particle size lower than $100 \mathrm{~nm}$. The rhizomatic, fibrous root and herbs are typically difficult to grind into nano size (Su et al., 2006) because of the higher fibre. Fibre strength and its diameter have much impact on the nanoparticle size. The presence of fibrous material may limit amount of cellular material to be ruptured thus interfering with the milling effectiveness (Rajkhowa et al., 2009; Rajkhowa et al., 2008).

In addition, the method used to produce nanoparticles also influences the size of the nanoparticles produced. Nanoparticles produced using a mechanical approach where it involved the breaking process of bigger particles into smaller particles with the presence of energy from mechanical devices are capable of producing nanoparticles typically in the 100 to $1000 \mathrm{~nm}$ range (Acosta, 2009). Table 1 indicated the sizes of the nanoparticles that were produced using a mechanical approach.

Table 1:- Particle Size of Nanoparticle that Produced Through Mechanical Approach.

\begin{tabular}{|l|l|l|}
\hline Material Tested & Everage Particle Size & References \\
\hline Wheat Bran Dietary Fibre Powder & $343.5 \mathrm{~nm}$ & Zhu et al. (2010) \\
\hline C. asiatica & Almost $500 \mathrm{~nm}$ & Borhan et al. (2014) \\
\hline Red mold rice & Almost $500 \mathrm{~nm}$ & Yu et al. (2006) \\
\hline Traditional Chinese Medicine Algar & $78 \pm 8.3 \mathrm{~nm}$ & Tian et al. (2014) \\
\hline Rhizama Chuanxiong & Around $200 \mathrm{~nm}$ & Su et al. (2006) \\
\hline Cuscuta chinensis & $267.6 \pm 4.4 . \mathrm{nm}$ & Yen et al. (2008) \\
\hline Liuwei Dihuang & $161.9 \pm 2.5 \mathrm{~nm}$ & Ma et al. (2009) \\
\hline Quercetin & $251.56 \pm 24.6 \mathrm{~nm}$ & Gao et al. (2011) \\
\hline Tea Tree Oil & $287 \pm 2 \mathrm{~nm}$ & Santos et al. (2014) \\
C. officinalis oil & $211.53 \pm 1.65 \mathrm{~nm}$ & \\
C. guaianensis oil & $192.36 \pm 1.30 \mathrm{~nm}$ & \\
\hline Chitosan & $372.2 \mathrm{~nm}$ & Zhang et al. (2012) \\
\hline Lycium. barbarum Polysaccharides & $378.7 \mathrm{~nm}$ & Zhang et al. (2014 \\
\hline
\end{tabular}

Changes in the structure and shape as well as surface morphology due to nanotechnology process are also reported. The strong mechanical impact introduced during the nanotechnology process switched the solid spherical shape of the coarse material into much smaller irregular flake like platelets as well as other shapes of smaller fragments (Liu et al., 2009; Ren et al., 2010; Zhao et al., 2010). While in another study by Lian et al. (2013) and Sun et al. (2014) revealed that the nanotechnology process shifted the FTIR peak absorption into a lower band, indicating that it caused some increment in the intermolecular force of hydroxyl groups. In addition, a decrease in the band height and broader $\mathrm{OH}$ - stretching vibration regions were also reported, which indicated crystalline structure degradation and formation of an amorphous structure (Xie et al., 2006). Huang et al. (2008) further revealed that the nanotechnology process decreased the peaks' intensity at $15^{\circ}, 17^{\circ}, 18^{\circ}$ and $23^{\circ}$, to the extent that they almost disappeared, leading to the development of a broad and featureless peak. This peak diffraction spectrum 
corresponded to a typical spectrum of amorphism. The transformation of a crystalline into an amorphous structure as a result of the nanotechnology process was also observed in switchgrass, jicama, maize starch and cassava starch (He et al., 2014; Huang et al., 2007; Jessica et al., 2014; Martinez Bustos et al., 2007). Moreover, in certain cases, a new functional group was formed affected by the nanotechnology process, as revealed by Wei et al. (2014), when new $\mathrm{C}=\mathrm{O}$ groups were observed in the nanochitosan which previously did not appear in its coarse particle.

The nanotechnology process is also found to affect the color intensity. Increases in the lightness intensity due to the particle size reduction were observed in corn silk and wheat bran (Cha et al., 2012; Majzoobi et al., 2014). While in another study by Tsai et al. (2011) they reported that more vivid redness intensities ( $\mathrm{a}^{*}$ value) of betanin and total betacyanin were observed in the nanoparticle $C$. formosanum as compared to the coarse particle. Meanwhile, a yellowness intensity ( $b^{*}$ value) increment was observed in the fine green tea when compared to the coarse particle sample as reported by $\mathrm{Hu}$ et al. (2012). The changes in the color intensity may contributed by the ability of the nanotechnology process to expose the inner layer of materials to the surroundings, hence altering the colour (Majzoobi et al., 2014).

Moreover, increased water holding capacity (WHC) with particle size reduction was reported in the superfine $A$. membranaceus powder (Zhao et al., 2010), A. chaxingu (Zhang et al., 2005), Z. officinale powder (Zhao et al., 2009), carrot (Chau et al., 2007) and buckwheat hull dietary fibre (Zhu et al., 2014). Exposure of more of the hydrophilic parts of cellulose and hemicelluloses to the water surroundings during the milling process was the reason for the WHC increment (Zhao et al., 2009).

The Effect of Nanotechnology Process on the Chemical Properties of Plants :-

Nanotechnology process has been found to cause various effects on the active constituents present and most of the studies found that the nanotechnology process enhanced the control release of active compounds (Giao et al., 2009; Zhao et al., 2011). Greater paeonol concentration was observed in nano L. dihuang as compared to its coarse particle (Ma et al., 2009). In addition, the nanotechnology process enhanced the active constituents in S. miltiorrhiza (Danshen) when the nanosalvianolic acid B concentration was reported to be $1.22 \mathrm{mg} / \mathrm{g}$ higher than the conventionally prepared one (Liu et al., 2008). Hence, it provided a general idea that maybe the milling process allowed more flavonoids out of the cell matrix. This was in agreement with Ma et al. (2009) who found that the physicochemical and medicinal characterisations of $L$. dihuang were optimised after being ground to $161.9 \mathrm{~nm}$. It was previously inconsistently absorbed in its coarse particle.

Furthermore the phenolic compound which includes phenolic acids and flavonoid, well known antioxidant agents found in plants are documented as being better isolated $(\mathrm{p}<0.05)$ when the particle is reduced to nanosize. Greater amounts of phenolic acids were extracted in the bitter melon, fibre rich powder and corn silk as well as in the djulis C. formosanum, after being exposed to the ultrafine and nanotechnology process application (Cha et al., 2012; Tsai et al., 2011; Zhu et al., 2012; Zhuang et al., 2012). Similar phenolic acid increase as a result of this technology was claimed by Jiechao (2011), Mayer-Miebach et al. (2012) and Majzoobi et al. (2014) where the percentage increased from $49 \%$ to $90 \%$ compared to its coarse particle as observed in the apple pomace powders, chokeberry and bitter melon powder. The results gained are relatively in agreement with Zhao et al. (2009) and Zhu et al. (2014), who suggested that size reduction technology, particularly the nanotechnology process, dramatically increase the total phenolic compound extractability.

Despite the effectiveness of the nanotechnology process in enhancing the release of some active compounds, depletion of other active compounds as a result of the nanotechnology process are reported. Reductions in the TFC were observed in the nano $C$. chinesis (Zhang et al., 2009) and nano pigmented rice (Paiva et al., 2014). In addition, depletion of folates, phytic acid and sinapic acid, as well as coumaric acid, were demonstrated in the wheat bran and fibre flax due to the nanotechnology process (Dyminska et al., 2012; Hemery et al., 2011). The compounds' stability during the nanotechnology process may contribute to the variation in the active constituents extracted. Pacheco-Palencia et al. (2008) claimed that $73.4 \%$ reduction in the ferulic acid took place during storage at $40^{\circ} \mathrm{C}$ for 10 weeks, while Reblova et al. (2012) stated that gallic acid is the most readily oxidised phenolic acid. In fact the instability is even worse than for ferulic acid. Active compounds' degradation as affected by the thermal effect is also an important reason for the loss of phenolic acids (Hemery et al., 2011). In brief, it reflects the stability of phenolic acids where at a certain level, some of the phenolic acids are found to be sensitive to heat. This argument was further supported by Kim et al. (2009) and Rawson et al. (2011) when, in their paper, they revealed that reductions in the gallic acid as well as total soluble phenolic acid were demonstrated in mango as a result of thermal 
effects. Heat generated during processing is reported to decrease the quercetin, kaempferol and myricetin concentration as observed in the cashew apple, mango, pitanga and acerola fruit (Chen et al., 2007; Hoffmann Ribani et al., 2009). Furthermore total losses of naringenin, quercetin and rutin in reduced sizes of A. eupatoria, Salvia sp. and S. montana particle were reported by Giao et al. (2009). In fact, Rawson et al. (2011) concluded that heat generated during the nanotechnology process most probably causes changes in the stability of bioactive compounds, which include ascorbic acid, polyphenol and carotenoids, due to their heat sensitivity. Moreover, the steps involved during the nanotechnology process may alter the structure of active components, thus limiting the extraction rate of the compounds and sometimes causing them to be undetectable through HPLC (Dyminska et al., 2012).

The smaller size of the nanoparticles improved the solubility and increased the dissolution rate of poor water soluble active ingredients thus reported to enhance the antioxidant activity. The nanotechnology process effectiveness in enhancing the antioxidant activity was described by Liu et al. (2008) where S. miltiorrhiza (Danshen) products prepared using the nanotechnology process exhibited more scavenging power compared to traditionally ground material based on the DPPH radical scavenging and ferrous ions chelating assays $(\mathrm{p}<0.05)$. Moreover, the reducing power of the S. miltiorrhiza (Danshen) was also significantly better than the traditional preparations. While in another study, increase in the ABTS radical scavenging activity, FRAP, accompanied by TPC increment was demonstrated in dietary fibre from buckwheat hulls that had undergone the size reduction process (Zhu et al., 2014). Antioxidant enhancement as a result of size reduction technology is also demonstrated in wheat bran as documented by Rosa et al. (2013) which is similar to the nanoparticle C. formosonum (Tsai et al., 2011), when this technology was found to be $8 \%$ and $38.02 \%$ better in antioxidant properties when compared to the coarse particle respectively. Significant improvement in the FRAP activity due to the nanotechnology process was also observed in the nanoparticle dietary fibre (Zhu et al., 2014) which was comparable to the chitosan nanoparticle (Pasanphan et al., 2015). While in another study, the nanotechnology process had improved the DPPH free radical inhibition of quercetin nanoparticles when the activity was found to be 883 fold higher than for its coarse particle (Wu et al., 2008). Similar remarkable free radical inhibition activity was documented by Zhang et al. (2009) and Tsai et al. (2011), when the nanotechnology process increased the antioxidant activity up to $92.84 \%$ and $80 \%$ in C. sinensis fruit and chitosan correspondingly.

Despite the success of the nanotechnology process, some authors revealed that this technology reduced some of the antioxidant activity as demonstrated in the dietary fibre from wheat bran (Brewer et al., 2014; Zhu et al., 2010) and dietary fibre from wine grape pomace (Zhu et al., 2014). The authors revealed that the nanotechnology process caused $47.95 \%, 9.59 \%, 3.8 \%$ reductions in the DPPH free radical inhibition activity respectively as compared to the coarse particle. This is supported by Tao et al. (2014) where size reduction technology caused a slight reduction in the DPPH free radical inhibition activity of ultrafine insoluble dietary fibre from citrus. This result was in agreement with Zhu et al. (2010) where wheat bran coarse particles showed significantly greater DPPH free radical inhibition percentage $(72.76 \%)$ compared to its nanoparticles $(24.81 \%)$. A similar trend in the DPPH free radical inhibition activity was also observed in the ultrafine dietary fibre from wine grape pomace where the DPPH free radical inhibition activity was $91.9 \%$ with $95.7 \%$ in its coarse particle (Zhu et al., 2014), while Brewer et al. (2014) reported that $55.88 \%$ DPPH free radical inhibition activity was found in the coarse particle compared to the fine particle $(46.29 \%)$ wheat bran. Thus, they made an assumption that the heat generated through mechanical milling damaged the total phenolic components and thus diminished their antioxidant activity. The stability of the active compounds with nanotechnology process, as well as inability of these active compounds to stand the heat generated along the process, may the possible reasons for antioxidant degradation, since some of the phenolic compounds are stable and some are unstable. In fact Brewer et al. (2014) emphasized that single electron transfer was at the optimum stage when fewer processing steps were involved. The greater amount of fibre found in the sample may extend the milling time, thus causing degradation of some of the active compounds.

However in certain cases, the effect of the nanotechnology process was depend on the antioxidant assay used to evaluate the antioxidant activity itself. As described in the study conducted on $C$. sinensis fruit, the author revealed that the nanotechnology process promotes the diminishing of the ferric reducing antioxidant power (FRAP), but at the same time, this technology was found to improve DPPH free radical inhibition activity (Zhang et al., 2009). Therefore they suggested that FRAP analysis may be adversely affected by particle size. Furthermore, the stability of antioxidant compounds and different targets of reactions may contribute to this variation. 


\section{Conclusion:-}

The nanotechnology application in plants and herbs is of great interest due to economic prospects, and feasibility and wide range of applications in food and agricultural science. It is an emerging research area in the scientific world and promise a bright future for this field. The nanotechnology process leads to some changes in the physicochemical properties and brings some novel characteristics that cannot be obtained in the larger materials. Nanotechnology process reported to increase the extraction yield and enhanced the bioactivity effectiveness. Additionally, the well dispersed nanoparticles may also contribute to the full dissolution of the active ingredients. Moreover, it is enhanced antioxidant activity in fact the activity would be equally effective as that of synthetic agent used in the food applications.

\section{References:-}

1. Borhan, M. Z., Ahmad, R., Rusop, M., \& Abdullah, S. (2014). Effect of nanonization on physicochemical properties of Centella asiatica Powders. Advanced Materials Research, 917, 106-112.

2. Bouwmeester, H., Dekkers, S., Noordam, M. Y., Hagens, W. I., Bulder, A. S., \& de Heer, C. (2009). Review of health safety aspects of nanotechnologies in food production. Regulatory Toxicology and Pharmacology, 53(1), $52-62$.

3. Brewer, L. R., Kubola, J., Siriamornpun, S., Herald, T. J., \& Shi, Y.C. (2014). Wheat bran particle size influence on phytochemical extractability and antioxidant properties. Food Chemistry, 152, 483-490.

4. Cha, S. M., Son, B. Y., Lee, J. S., Baek, S. B., Kim, S. L., \& Ku, J. H. (2012). Effect of particle size on physicochemical properties and antioxidant activity of corn silk powder. Korean Journal of Crop Science, 57(1), 41-50.

5. Chau, C.F., Wang, Y.T., \& Wen, Y.L. (2007). Different micronization methods significantly improve the functionality of carrot insoluble fibre. Food Chemistry, 100(4), 1402-1408.

6. Chen, J. P., Tai, C. Y., \& Chen, B. H. (2007). Effects of different drying treatments on the stability of carotenoids in Taiwanese mango (Mangifera indica L.). Food Chemistry, 100, 1005-1010.

7. Dyminska, L., Szatkowski, M., Wrobel Kwiatkowska, M., Zuk, M., Kurzawa, A., Syska, W. (2012). Improved properties of micronized genetically modified flax fibers. Journal of Biotechnology, 164, 292-299.

8. Gao, L., Liu, G., Wang, X., Liu, F., Xu, Y., \& Ma, J. (2011). Preparation of a chemically stable quercetin formulation using nanosuspension technology. International Journal of Pharmaceutics, 404(1-2), 231-237.

9. Giao, M. S., Pereira, C. I., Fonseca, S. C., Pintado, M. E., \& Malcata, F. X. (2009). Effect of particle size upon the extent of extraction of antioxidant power from the plants Agrimonia eupatoria, Salvia sp. and Satureja montana. Food Chemistry, 117, 412-416.

10. He, S., Qin, Y., Walid, E., Li, L., Cui, J., \& Ma, Y. (2014). Effect of ball-milling on the physicochemical properties of maize starch. Biotechnology Reports, 3(0), 54-59.

11. Hemery, Y., Chaurand, M., Holopainen, U., Lampi, A.M., Lehtinen, P., \& Piironen, V. (2011). Potential of dry fractionation of wheat bran for the development of food ingredients, part I: Influence of ultra-fine grinding. Journal of Cereal Science, 53(1), 1-8.

12. Hoffmann Ribani, R., Huber, L. S., \& Rodriguez Amaya, D. B. (2009). Flavonols in fresh and processed Brazilian fruits. Journal of Food Composition and Analysis, 22, 263-268.

13. $\mathrm{Hu}$, J., Chen, Y., \& Ni, D. (2012). Effect of superfine grinding on quality and antioxidant property of fine green tea powders. LWT-Food Science and Technology, 45, 8-12.

14. Huang, Z. Q., Lu, J. P., Li, X. H., \& Tong, Z. F. (2007). Effect of mechanical activation on physicochemical properties and structure of cassava starch. Carbohydrate Polymers, 68(1), 128-135.

15. Huang, Z. Q., Xie, X. L., Chen, Y., Lu, J. P., \& Tong, Z. F. (2008). Ball-milling treatment effect on physicochemical properties and features for cassava and maize starches. Comptes Rendus Chimie, 11, 73-79.

16. Jessica, D. M., Elizabeth, A. W., \& B., J. J. (2014). Characterisation of milling effects on the physical and chemicalnature of herbaceous biomass with comparison of fast pyrolysisproduct distributions using Py-GC/MS. Journal of Analytical and Applied Pyrolysis, 108, 234-247.

17. Jiechao, L., Zhonggao, J., Xinhong, L., Lei, H., \& Liu, L. (2011). Effect of ultrafine pulverization on properties of apple pomace powder. Advanced Materials Research, 236-238, 2560-2563.

18. Kazemimostaghim, M., Rajkhowa, R., Tsuzuki, T., \& Wang, X. (2013). Production of submicron silk particles by milling. Powder Technology, 241, 230-235.

19. Kim, J. Y., \& Lim, S. T. (2009). Preparation of nano-sized starch particles by complex formation with nbutanol. Carbohydrate Polymers, 76, 110-116. 
20. Lian, X. J., Liu, L. Z., Guo, J. J., Li, L., \& Wu, C. Y. (2013). Screening of seeds prepared from retrograded potato starch to increase retrogradation rate of maize starch. International Journal of Biological Macromolecules, 60, 181-185.

21. Liu, J. R., Chen, G. F., Shih, H. N., \& Kuo, P. C. (2008). Enhanced antioxidant bioactivity of Salvia miltiorrhiza (Danshen) products prepared using nanotechnology. Phytomedicine, 15(1-2), 23-30.

22. Liu, D. G., Wu, Q. L., Chen, H. H., \& Chang, P. R. (2009). Transitional properties of starch colloid with particle size reduction from micro to nanometer. Journal of Colloid and Interface Science, 339, 117-124.

23. Ma, P. Y., Fu, Z. Y., Su, Y. L., Zhang, J. Y., Wang, W. M., \& Wang, H. (2009). Modification of physicochemical and medicinal characterisation of Liuwei Dihuang particles by ultrafine grinding. Powder Technology, 191(1-2), 194-199.

24. Majzoobi, M., Pashangeh, S., Farahnaky, A., Eskandari, M. H., \& Jamalian, J. (2014). Effect of particle size reduction, hydrothermal and fermentation treatments on phytic acid content and some physicochemical properties of wheat bran. Journal of Food Science Technology, 51(10), 2755-2761.

25. Martinez Bustos, F., Lopez Soto, M., San Martin Martinez, E., Zazueta Morales, J. J., \& Velez Medina, J. J. (2007). Effects of high energy milling on some functional properties of jicama starch (Pachyrrhizus erosus L. Urban) and cassava starch (Manihot esculenta Crantz). Journal of Food Engineering, 78(4), 1212-1220.

26. Mayer-Miebach, E., Adamiuk, M., \& Behsnilian, D. (2012). Stability of chokeberry bioactive polyphenols during juice processing and stabilization of a polyphenol-rich material from the by-product. Agriculture, 2, 244258.

27. Pacheco Palencia, L. A., Duncan, C. E., \& Talcott, S. T. (2009). Phytochemical composition and thermal stability of two commercial acai species, Euterpe oleracea and Euterpe precatoria. Food Chemistry, 115, 11991205.

28. Pasanphan, W., Rattanawongwiboon, T., Choofong, S., Guven, O., \& Katti, K. (2015). Irradiated chitosan nanoparticle as a water-based antioxidant and reducing agent for a green synthesis of gold nanoplatforms. Radiation Physics and Chemistry, 106, 360-370.

29. Paiva, F. F., Vanier, N. L., Berrios, J. D. J., Pan, J., Villanova, F. A., \& Takeoka, G. (2014). Physicochemical and nutritional properties of pigmented rice subjected to different degrees of milling. Journal of Food Composition and Analysis, 35, 10-17.

30. Rajkhowa, R., Wang, L., Kanwar, J., \& Wang, X. (2009). Fabrication of ultrafine powder from eri silk through attritor and jet milling. Powder Technology, 191(1-2), 155-163.

31. Rajkhowa, R., Wang, L., \& Wang, X. (2008). Ultra-fine silk powder preparation through rotary and ball milling. Powder Technology, 185(1), 87-95.

32. Rawson, A., Patras, A., Tiwari, B. K., Noci, F., Koutchma, T., \& Brunton, N. (2011). Effect of thermal and non thermal processing technologies on the bioactive content of exotic fruits and their products: Review of recent adances. Food Research International, 44, 1875-1887.

33. Reblova, Z. (2012). Effect of temperature on the antioxidant activity of phenolic acids. Czech Journal of Food Sciences, 30(2), 171-177.

34. Ren, G.Y., Li, D., Wang, L.J., Ozkan, N., \& Mao, Z. H. (2010). Morphological properties and thermoanalysis of micronized cassava starch. Carbohydrate Polymers, 79(1), 101-105.

35. Rosa, N. N., Barron, C., Gaiani, C., Dufour, C., \& Micard, V. (2013). Ultra-fine grinding increases the antioxidant capacity of wheat bran. Journal of Cereal Science, 57(1), 84-90.

36. Sabourin, V., \& Ayande, A. (2015). Commercial oppurtunities and market demand for nanotechnologies in agrobusiness sector. Journal Of Technology Management And Innovation, 10(1), 40-52.

37. Santos, R. C. V., Alves, A. F. S., Fausto, V. P., Pizzutti, K., Barboza, V. (2014). Antimicrobial activity of tea tree oil nanoparticles against American and European foulbrood diseases agents. Journal of Asia-Pacific Entomology, 17, 343-347.

38. Su, Y. L., Fu, Z.Y., Quan, C. J., \& Wang, W. M. (2006). Fabrication of nano Rhizama Chuanxiong particles and determination of tetramethylpyrazine. Transactions of Nonferrous Metals Society of China, 16(Supplement 1), S393-S397.

39. Sun, Q., Fan, H., \& Xiong, L. (2014). Preparation and characterisation of starch nanoparticles through ultrasonic-assisted oxidation methods. Carbohydrate Polymers, 106(0), 359-364.

40. Tao, B., Ye, F., Li, H., Hu, Q., Xue, S., \& Zhao, G. (2014). Phenolic profile and in vitro antioxidant capacity of insoluble dietary fiber powders from citrus (Citrus junos Sieb. ex Tanaka) pomace as affected by ultrafine grinding. Journal of Agricultural and Food Chemistry, 62, 7166-7173. 
41. Tian, Y., Wang, X., Xi, R., 2, Pan, W., Jiang, S., \& Li, Z. (2014). Enhanced antitumor activity of realgar mediated by milling it to nanosize. International Journal of Nanomedicine, 9, 745-757.

42. Tsai, P. J., Chen, Y. S., Sheu, C. H., \& Chen, C. Y. (2011). Effect of nanogrinding on the pigment and bioactivity of Djulis (Chenopodium formosanum Koidz.). Journal Agricultural Food Chemistry, 59, $1814-1820$.

43. Wei, Z., Jiali, Z., \& Wenshui, X. (2014). Effect of ball-milling treatment on physicochemical and structural properties of chitosan. International Journal of Food Properties, 17(1), 26-37.

44. Wu, T. H., Yen, F. L., Lin, L. T., Tsai, T. R., Lin, C. C., \& Cham, T. M. (2008). Preparation, physicochemical characterisation, and antioxidant effects of quercetin nanoparticles. International Journal of Pharmaceutics, 346(1-2), 160-168.

45. Xie, X., Liu, Q., \& Cui, S. W. (2006). Studies on the granular structure of resistant starches (type 4) from normal, high amylose and waxy corn starch citrates. Food Research International, 39(3), 332-341.

46. Yen, F. L., Wua, T. H., Lin, L. T., Cham, T. M., \& Lin, C. C. (2008). Nanoparticles formulation of Cuscuta chinensis prevents acetaminophen-induced hepatotoxicity in rats. Food and Chemical Toxicology, 46, 17711777.

47. Yu, C. C., Lee, C. L., \& Pan, T. M. (2006). A novel formulation approach for preparation of nanoparticulate red mold rice. Journal Agricultural Food Chemistry, 54(18), 6845-6851.

48. Zhang, M., Zhang, C. J., \& Shrestha, S. (2005). Study on the preparation technology of superfine ground powder of Agrocybe chaxingu Huang. Journal of Food Engineering, 67, 333-337.

49. Zhang, L. H., Xu, H. D., \& Li, S. F. (2009). Effects of micronization on properties of Chaenomeles sinensis (Thouin) Koehne fruit powder. Innovative Food Science \& Emerging Technologies, 10(4), 633-637.

50. Zhang, W., Zhang, J., Jiang, Q., \& Xia, W. (2012). Physicochemical and structural characteristics of chitosan nanopowders prepared by ultrafine milling. Carbohydrate Polymers, 87, 309-313.

51. Zhang, M., Wang, F., Liu, R., Tang, X., Zhang, Q., \& Zhang, Z. (2014). Effects of superfine grinding on physicochemical and antioxidant properties of Lycium barbarum polysaccharides. LWT - Food Science and Technology, 58, 594-601.

52. Zhao, X., Yang, Z., Gai, G., \& Yang, Y. (2009). Effect of superfine grinding on properties of ginger powder. Journal of Food Engineering, 91(2), 217-222.

53. Zhao, X., Du, F., Zhu, Q., Qiu, D., Yin, W., \& Ao, Q. (2010). Effect of superfine pulverization on properties of Astragalus membranaceus powder. Powder Technology, 203, 620-625.

54. Zhao, G., Wang, C., Liao, Z., Liang, X., Cao, Y., \& Chen, X. (2011). Comparative study of physicochemical properties of dragon's blood powders. Advanced Materials Research, 311-313, 560-565.

55. Zhu, K., Huang, S., Peng, W., Qian, H., \& Zhou, H. (2010). Effect of ultrafine grinding on hydration and antioxidant properties of wheat bran dietary fiber. Food Research International, 43(4), 943-948.

56. Zhu, Y., Dong, Y., Qian, X., Cui, F., Guo, Q., \& Zhou, X. (2012). Effect of superfine grinding on antidiabetic activity of bitter melon powder. International Journal of Molecular Science, 13, 14203-14218.

57. Zhu, F., Du, B., Li, R., \& Li, J. (2014). Effect of micronization technology on physicochemical and antioxidant properties of dietary fiber from buckwheat hulls. Biocatalysis and Agricultural Biotechnology, 3(3), 30-34.

58. Zhuang, Y., Zhang, Y., \& Sun, L. (2012). Characteristics of fibre-rich powder and antioxidant activity of pitaya (Hylocereus undatus) peels. International Journal of Food Science and Technology, 47, 1279-1285. 